\title{
Can social prescribing provide the missing link?
}

\author{
Jane South ${ }^{1}$, Tracy J. Higgins ${ }^{2}$, James Woodall ${ }^{1}$ and Simon M. White ${ }^{2}$ \\ ${ }^{1}$ Leeds Metropolitan University, Leeds, UK \\ ${ }^{2}$ Bradford \& Airedale tPCT, Bradford, UK
}

\begin{abstract}
Background: The voluntary sector has long been recognised as making an important contribution to individual and community health. In the UK, however, the links between primary health care services and the voluntary and community sector are often underdeveloped. Social prescribing is an innovative approach, which aims to promote the use of the voluntary sector within primary health care. Social prescribing involves the creation of referral pathways that allow primary health care patients with non-clinical needs to be directed to local voluntary services and community groups. Such schemes typically use community development workers with local knowledge who are linked to primary health care settings. Social prescribing therefore has the potential to assist individual patients presenting with social needs to access health resources and social support outside of the National Health Service. Aim: The aim of this paper is to explore the concept of social prescribing and discuss its value as a public health initiative embedded within general practice. Methods: The rationale for social prescribing and existing evidence are briefly reviewed. The paper draws on a case study of a pilot social prescribing scheme based in general practice. Data collected during the development, implementation and evaluation of the scheme are used to illustrate the opportunities and limitations for development in UK primary health care. Findings: The potential for social prescribing to provide a mediating mechanism between different sectors and address social need is discussed. The paper argues that social prescribing can successfully extend the boundaries of traditional general practice through bridging the gap between primary health care and the voluntary sector. The potential for wider health gain is critically examined. The paper concludes that social prescribing not only provides a means to alternative support but also acts as a mechanism to strengthen community-professional partnerships. More research is needed on the benefits to patients and professionals.
\end{abstract}

Key words: general practice; social needs; social prescribing; voluntary sector

Received: 7 March 2008; accepted: 22 August 2008

\section{Introduction}

Public health and primary care in the UK have been described as having a 'necessary relationship' but one defined by its complexity (Busby et al., 1999). Notwithstanding drives to embed the

Correspondence to: Jane South, Centre for Health Promotion Research, Queen Square House, G08, Leeds Metropolitan University, Leeds LS1 3HE, UK. Email: j.south@leedsmet. ac.uk

(C) 2008 Cambridge University Press public health agenda within the role of primary care organisations, the core business remains based on clinicians providing individual care and treatment (Godinho et al., 1992; Department of Health, 2002; Peckham and Exworthy, 2003; Secretary of State for Health, 2006). While many public health initiatives attempt to engage the 'hard-to-reach', general practice remains a key point of access, including for those presenting with social needs. Provision and utilisation of services is not necessarily indicative of the capacity 
to meet health need. Despite the potential benefits, voluntary sector support often remains underused because links between health services and community organisations are weak or nonexistent. Social prescribing is a new approach in primary care, which promotes the use of the community and voluntary sector. It is generating interest as an approach that can bridge the gap between health services and health needs through signposting and support. The aim of this paper is to explore the concept of social prescribing and critically examine its value as a public health initiative embedded within primary care. The paper draws on a case study of the development and evaluation of a social prescribing scheme to reflect on the opportunities and constraints in developing this type of initiative.

\section{The rationale for social prescribing}

Health service resources are under increasing pressure in the UK and it is envisaged that voluntary organisations, as part of what is termed the third sector, will play an increasing part in the provision of primary care services (Coid et al., 2003; Department of Health, 2004; Secretary of State for Health, 2006). Voluntary and community organisations complement statutory services by responding to local needs informally and by filling service gaps (Ward, 2001; Milne et al., 2004; Secretary of State for Health, 2006). This can include both the provision of health information and support services by national organisations through to small scale local activity such as self-help groups or community-based social activities, for example, luncheon clubs and walking groups. Crombie and Coid (2000) suggest that given the range of voluntary organisations, there is likely to be one to help every patient presenting in the National Health Service (NHS). They note that support organisations exist for a host of rarer conditions as well as for the major disease groups. Voluntary sector provision is generally rooted in values such as empowerment, promoting rights and engaging with people on their own terms (Wakeling, 1999). Such a provision can fulfil a vital role in addressing public health issues through education, advocacy and support. This has particular significance in the context of health inequalities where voluntary organisations work with communities whose health needs are not met by mainstream services. One major challenge for public health is developing effective partnerships to harness voluntary sector resources within communities, thereby improving access to the range of support available.

Social prescribing has emerged as a mechanism for linking people using primary care with support in the community (Brown et al., 2004). The gap between primary care and voluntary organisations is bridged through community development workers who have detailed local knowledge, thereby ensuring appropriate signposting for individuals (Bromley NHS Primary Care Trust, 2001). Friedli and Watson (2004) suggest that social prescribing has benefits in three key areas: improving mental health outcomes for patients, improving community well-being and reducing social exclusion. The point here is that putting individuals in touch with local voluntary organisations and groups has the potential to impact not only directly on mental and physical health but also indirectly through increased social contacts, improved access to services and ultimately improved social networks within communities. Brown et al. (2004) comment on the relevance of this to disadvantaged and vulnerable groups who might normally face barriers to service use.

Social prescribing is a relatively new concept with only a small number of schemes in UK practice and as such there is a limited evidence base (Brown et al., 2004). A randomised controlled trial of the Amalthea Project (Grant et al., 2000) examined general practice patients with psychosocial problems given access to voluntary organisations. At one and four months after randomisation, those assigned to the intervention group had significant improvements in anxiety, improved ability to carry out everyday activities and improved feelings about general health and quality of life. Another study found that a voluntary referral scheme had successfully utilised the voluntary sector to support patients. The scheme was reported to be an important adjunct to traditional approaches of referral in general practice, acting as: 'a linchpin between the professional role of medicine and the voluntary world of psychosocial support' (Faulkner, 2004, p. 46). Likewise, comparable referral and signposting schemes based in general practice have been shown to be effective at addressing social 
needs (Clarke et al., 2001; Aylward and James, 2002).

The benefits for individuals when access to support is facilitated are evident; however, it can be argued that such mechanisms result in the transfer of service users to other sectors, thereby shelving underlying problems. This in turn raises questions about whether social prescribing represents a 'joined up' solution to social issues seen in primary care or is it merely a 'bolt-on' to predominately clinical services. The significance of social prescribing as a mediating mechanism between different sectors will now be explored in a case study of the development and implementation of one scheme.

\section{Social prescribing in practice - a case study}

The Community Health Advice Team (CHAT) is a social prescribing scheme established by Bradford South and West Primary Care Trust (PCT) in 2005. The aims of the scheme were to broaden service provision for patients with nonclinical needs and to facilitate links between primary care and the community and voluntary sector. A CHAT worker, with community development experience, was appointed to develop and deliver the scheme in two general practices both located in disadvantaged urban areas. The scheme has since been extended to a third practice. In relation to the referral process, patients either refer themselves, via a tear-off slip on leaflets that are on display in the surgery or local pharmacies, or are referred by general practitioners and other practice staff including practice nurses, health visitors and receptionists. The health professionals complete a simple referral form that asks for contact details, the reason for referral and who the referrer is. The client is then contacted within seven days to arrange an appointment. Although people are encouraged to come to their local general practice surgery, it is possible for home visits to be arranged. Up to three appointments of approximately up to $40 \mathrm{~min}$ each are held with clients to discuss their needs and to then identify an appropriate source of local support. The CHAT worker facilitates access to local organisations, predominately from the voluntary and community sector and also including some

\section{Box 1 Examples of groups and services used by CHAT}

\author{
Luncheon clubs \\ Befriending groups \\ Social services \\ Volunteering organizations \\ Getting back into work groups \\ Literacy classes \\ Debt advice \\ Access bus \\ Bereavement groups \\ Reminiscing groups \\ Arts and craft groups \\ Music groups
}

alternative statutory services (see Box 1 for examples). The worker may accompany clients on their first visit in cases where clients lack confidence or require additional support. There is one follow-up appointment to check on the progression of the client and ascertain their views on the organisations visited. The CHAT worker liaises with health professionals as required and sometimes meets with referrers to the discuss management of client needs. At the end of the process, the referring health professional is given a written account of what has taken place and what services the patient has been offered.

\section{Methods}

The case study emerged from a process of co-operative enquiry that sought to deepen the understandings of how and why social prescribing worked in this context (Reason and Heron, 2004). A formative evaluation, undertaken by two of the authors (Woodall and South, 2005), was part of that process. Qualitative methodology was used for the evaluation in order to understand how the scheme operated within a specific social context and to examine the acceptability and relevance of the scheme (Patton, 1987). Semi-structured individual interviews were undertaken with 10 clients and eight health professionals. Clients were purposively sampled from a database of individuals who had participated in the CHAT scheme and had expressed an interest in contributing to an evaluation of 
the service. The construction of the sampling frame reflected the diversity of CHAT clients in relation to their gender and age as well as to their frequency of service use and complexity of need. Clients who were selected were contacted to discuss the evaluation and the possibility of participating in a confidential interview with a member of the research team. Individuals who declined to participate at this point were thanked for their time and additional clients were then re-sampled.

Health professionals were selected on the basis of their professional role, their experience of the CHAT service and the number of referrals made. All health professionals who were selected to take part in the evaluation accepted. The composition of the health professional sample included three general practitioners, two practice managers, two nurse practitioners and a healthyliving centre co-ordinator. All interviews were taped, transcribed and analysed thematically. A small number of anonymous quotations derived from the evaluation are used in the paper to highlight discussion points. In addition, monitoring data on client characteristics and social need covering the first 15 months of operation (between May 2005 and October 2006) are also presented. The categories were developed inductively; presenting issues were categorised by the social prescribing worker based on the initial assessment of the client. As part of the collaboration, structured discussions were held with the public health manager and the social prescribing worker over the course of the scheme development and detailed notes were taken. The paper focuses on three key issues that emerged through those discussions:

- How does social prescribing fit within primary care?

- What is its contribution as a public health intervention?

- Can social prescribing form part of a strategic approach to building links with the voluntary sector?

\section{Extending primary care}

In 2005, the PCT was funding a small number of local and districtwide voluntary and community organisations, but, in most cases, there were no connections to primary care services. It was recognised that health professionals were not signposting patients because they were unaware of the breadth and variety of available services. Learning from another scheme indicated that social prescribing was more effective with a dedicated worker based in general practice, as opposed to being managed and delivered externally (Bromley NHS Primary Care Trust, 2001). It was therefore agreed that the CHAT worker would be part of the PCT Public Health Team but be based, at least for a proportion of their working week, in the pilot practices.

Participating practices were involved in recruitment and selection; however, this process exposed differences in the models of health valued by individual panel members. The CHAT worker was required to have good knowledge of the voluntary sector and of community development principles and practice. These qualities are very different from those traditionally valued in primary care but eventually a common understanding of the purpose of the scheme was forged. Individuals representing the practices later became champions of the scheme, which led to a smooth implementation and early integration of the worker into the primary health care team.

The evaluation later found that health professionals felt comfortable referring patients due to high levels of trust and confidence in the CHAT worker's ability to find appropriate voluntary services. Sherratt et al. (2000) suggest that specialist advice workers are appreciated as they provide a better service to patients and also save staff time. Referring patients to a single known person reassured clinicians that the referral would be dealt with appropriately. One individual contrasted this to other external schemes where they were referring people 'into a black hole'.

The issue of location is evidently significant for social prescribing, not only for the primary health care team but also in terms of improving access. The question of integration goes beyond the challenge of providing a seamless service and touches on the extent to which alternative approaches to health improvement can co-exist (Levenson and Johnson, 2000). Our experience is that social prescribing does not exacerbate conflict but instead extends traditional primary care. One general practitioner described the benefits as 'having that extra something you can do for patients'. 
There are enormous challenges for primary care in urban disadvantaged areas (Royal College of General Practitioners, 2005), and research indicates that health professionals are aware of the impact of poverty on health (Daykin and Naidoo, 1997). The CHAT scheme illustrates how social prescribing can offer the opportunity to address social needs through individual consultations. An added bonus may be the reduction of workload and more capacity to focus on medical problems. Hence far from being about shifting responsibilities and transferring so-called problem patients, we argue that social prescribing should be seen as one way of extending primary care through partnership working.

\section{A public health intervention?}

A claim can be made that social prescribing, through addressing the wider determinants of health, represents a reorientation of health services, albeit one limited in scale and scope. A key question is the extent to which such schemes are able to reduce health inequalities and improve access to health resources. Monitoring data from CHAT demonstrate that the scheme is used by a wide range of people and it is noteworthy that there has been success in attracting men and also younger age groups (Table 1). There is a spread of presenting issues (Table 2), confirming the underlying demand for support and advice services located in primary care (Greasley and Small, 2005). The majority of referrals came through health professionals; $37 \%$ through general practitioners and 38\% through nursing staff while only $18 \%$ were self-referrals.

Social prescribing aims to provide a holistic package of support tailored to individual need.
Reflecting on the CHAT experience, for some the initial appointment is all that is needed, as this can give the necessary space for reflection as individuals benefit from the process of being listened to and starting to voice their aspirations. It is not suitable for those who require an intensive package of support and the limit on number of appointments prevents dependency. The evaluation found that the longer appointment time in comparison to clinical consultations was valued, as was the offer to accompany the client to a new group. In the interviews, clients identified benefits including social inclusion, feeling 'part of something', meeting new people through community groups and increased confidence. The case studies in Box 2 illustrate the indirect and direct benefits gained from accessing community resources and receiving low-level support through primary care.

The prominence of psychosocial problems has been described as a 'distinguishing feature' of general practice (Brooke and Sheldon cited in Gulbrandson et al., 1999) and social factors have

Table 2 Presenting issues

\begin{tabular}{lc}
\hline Presenting issue & Numbers (\%) \\
\hline Social isolation & $102(45)$ \\
Housing/benefits & $35(16)$ \\
Training & $23(10)$ \\
Family issues & $20(9)$ \\
Volunteering & $17(8)$ \\
Feels useless & $10(4)$ \\
Disabilities & $9(4)$ \\
Bereavement & $7(3)$ \\
Exercise & $2(1)$ \\
Total & $225(100)$ \\
\hline
\end{tabular}

Source: Monitoring data, May 2005-October 2006.

Table 1 Social prescribing clients - age and sex

\begin{tabular}{lccc}
\hline Age & Female & Male & Total (\%) \\
\hline $16-25$ & 25 & 9 & $34(15)$ \\
$26-35$ & 18 & 11 & $29(13)$ \\
$36-45$ & 26 & 10 & $36(16)$ \\
$46-55$ & 21 & 18 & $39(18)$ \\
$56-65$ & 8 & 10 & $18(8)$ \\
Over 65 & 40 & 13 & $53(24)$ \\
Age not recorded & 10 & 4 & $14(6)$ \\
Total & $148(66)$ & $75(34)$ & $223(100)$ \\
\hline
\end{tabular}

Source: Monitoring data, May 2005-October 2006.

Primary Health Care Research \& Development 2008; 9: 310-318 


\section{Box 2 Case studies of CHAT clients}

A very elderly woman living on her own managed very capably. The only real problem was that her eyesight was deteriorating rapidly and she loved to read. She had tried listening to taped books, but she was missing company during the day and she liked to discuss the books she was reading. She was put in touch with a befriending service and an arrangement was made that a volunteer would visit once a week to read together. This arrangement was still continuing over 12 months later.

A young woman described being bored at home now that her two young children were both at school. Ideally she wanted to get into work but had no qualifications. She was accompanied to a local voluntary organisation where she met the staff and decided she wanted to do a basic IT course, one half day a week. From this course she went to another, and with the help of the organisation, she secured a job.

One elderly woman was very isolated at home. In the consultation with the CHAT worker it became apparent that she used to love to dance but she very rarely left the house as she was quite scared. A local community group was contacted and they agreed to pick her up one day a week, and take her to their regular dance. The lady did not dance there, but she really enjoyed the music and the company.

One man had a full time job but he was spending beyond his means and was so stressed about it that he had been off work for several months. The CHAT worker arranged for him to see a local debt adviser, who helped with his financial position. He continued to be seen by CHAT to re-build his confidence. He returned to work and, in his own words, he 'got his life back'.

been found to be associated with frequent attendance (Vedsted and Christensen, 2005; Zantinge et al., 2005). Busby et al. (1999 write:

The difficulties and dilemmas inherent in understanding the full complexity of the relationship between an individual patent, his or her biography and the wider circumstances of history and economic change is faced most squarely by practitioners in primary care.

The limitations of clinical practice are illustrated by a general practitioner in the evaluation:

There's no point fixing them up physically and ignoring the housing benefit or the fact they can't read and write, and if I can't fix it I want to be able to point them in the right direction.

Given the impact on practice, it would seem logical that primary care plays a part in addressing the wider determinants. The challenge is how to incorporate a public health approach alongside the provision of quality, patient-centred care.
Social prescribing is based on a similar model to welfare benefits advice in primary care that has potential for increasing access to support and advice within health service settings (Sherratt et al., 2000; Greasley and Small, 2005; Adams et al., 2006). Abbott (2002) critically examined the case for welfare benefits advice in primary care as a health intervention. He argues that although welfare benefits advice is likely to have a minimal impact on the environmental determinants of community health, in this case poverty and deprivation, it should be valued because of the potential effect on the psychological status of individuals through the reduction of anxiety and stress. He concludes that while the imperative to address health inequalities is paramount, primary care has a part to play. These conclusions can be applied equally to social prescribing. As an intervention it does not address underlying problems in communities, such as social isolation, but it does mitigate the impact on individual health and enable people with social needs to make positive choices. Signposting to local organisations promotes community engagement, which has additional benefits (Rogers and 
Robinson, 2004). The potential for wider health gain is due to the 'distinctive value' of the voluntary sector in terms of the development of social capital and social networks in communities (Bolton, undated). Overall, we argue that the combination of individualised support and linking to community resources makes social prescribing an appropriate public health intervention for primary care.

\section{Building health alliances}

'Making Partnerships Work' (Department of Health, 2004) promotes a deeper and more meaningful engagement between the NHS and the community and voluntary sector. Over 3000 voluntary and community organisations exist in Bradford district; part of the aim of the CHAT scheme was to raise the profile of that sector and to formalise and streamline patient introductions to local organisations. One client spoke of how participation on the scheme had 'opened their eyes' to services in the local area:

I didn't realise there was all these things that were going on around me especially where I live...it's nice to know that there are things like that available.

There can also be an educational element in terms of increasing health professionals' awareness and understanding of voluntary organisations.

A Royal College of General Practitioners briefing (Royal College of General Practitioners, 2005, p. 4) noted that 'connecting with the plethora of voluntary sector services' can be 'very challenging' for inner-city general practitioners. Without a mediating mechanism, better integration is unlikely to happen spontaneously and there is evidence that project workers can play a key bridging role (Peckham et al., 1998; Fawcett and South, 2005). While the CHAT scheme has been pioneered in what might be termed traditional general practice, social prescribing could be embedded within more radical community development approaches within primary care (Fisher, 2001; Crowley et al., 2002). There is certainly potential to build health alliances but further research is needed to examine whether social prescribing leads to changes in health professionals' knowledge, attitudes and use of the community and voluntary organisations.

Primary Health Care Research \& Development 2008; 9: 310-318
Social prescribing is dependent on the existence of a flourishing voluntary and community sector. Crombie and Coid (2000) question the wisdom of portraying the voluntary sector as a 'white knight' coming to the rescue. Variety in terms of size, function, ownership and governance and funding (Taylor, 1997; Social Services Inspectorate, 2000) raises inevitable questions about capacity and the level of strategic funding and support needed from statutory agencies. Although flexible, voluntary organisations have a degree of instability that can affect access and impact on support (Coid et al., 2003). Quality and accountability issues may also be present (Johnson et al., 1998; Weir, 2002). In areas where there is an absence of a strong community and voluntary sector, such as some rural areas (Milligan, 1998), social prescribing may be inappropriate.

As with any approach that seeks to work across sectors, there are issues over commissioning, management and provision. The CHAT model, based in primary care but funded through public health, is only one of a range of possibilities. Social prescribing could potentially be provided through community mental health services, social services, in the voluntary sector or be delivered within public health programmes. The onset of practice-based commissioning and social enterprises (Department of Health, 2006, 2007) creates both threats and opportunities. There are also questions about how social prescribing fits with the new role of health trainers, lay people trained to provide individual support around behaviour change. Issues around contracting and provision are not simply a matter of defining roles, they touch on fundamental debates about the boundaries of state (free) provision, voluntarism and the role of communities in health (Lewis, 1999). There is a small but significant risk for public health that the greater integration of voluntary and community sector in primary care will result in less emphasis on advocacy and campaigning (Milligan, 1998).

\section{Conclusion}

Traditionally, many community health initiatives have developed outside primary care settings and the challenge is to integrate public health 
into mainstream primary care. Social prescribing offers a way to address some of the wider determinants of health through routine clinical services. It deals with the paradox that people use primary care for social needs, despite the fact that those services are 'inappropriate'. The fact they enter the health system should be viewed as an opportunity for signposting and support. We argue that social prescribing extends the boundaries of mainstream primary care to the benefit of patients and professionals. It offers a mechanism by which the gap between primary care and the community and voluntary sector can be bridged in order to provide support tailored to individual needs.

Few would argue that social prescribing is a magic bullet. It is unlikely to transform people's lives nor does it detract from the need to address health inequalities through macro-economic policies and public health programmes. There is a need for clarity about what this type of intervention can offer and more research to provide a strong evidence base. What social prescribing can offer above and beyond a provision of alternative support is a practical route to strengthen community-professional partnerships.

\section{Acknowledgements}

The development of the CHAT scheme was funded through Bradford South and West Primary Care Trust. The Centre for Health Promotion Research was commissioned by the Primary Care Trust to conduct an evaluation of the scheme.

\section{References}

Abbott, S. 2002: Prescribing welfare benefits advice in primary care: is it a health intervention, and if so, what sort? Journal of Public Health Medicine 24, 307-12.

Adams, J., White, M., Moffat, S., Howel, D. and Mackintosh, J. 2006: A systematic review of the health, social and financial impacts of welfare rights advice delivered in healthcare settings. BMC Public Health 6 doi:10.1186/14712458/6/81.

Aylward, N. and James, K. 2002: Prescriptions for learning project, 2nd evaluation report. Nottingham: Nottingham HAZ.

Bolton, M. Undated: Voluntary sector added value: A discussion paper. Retrieved 18 February 2008 from http:// www.ncvo-vol.org.uk/policy/index.asp?id=1372\&terms $=$ negotiating
Bromley NHS Primary Care Trust. 2001: Penge \& Anerley Community Health Project. "A social pill for every ill”: seminar report. London: Bromley NHS Primary Care Trust, Penge and Anerley Community Health Project, NHS Beacon Services.

Brown, M., Friedli, L. and Watson, S. 2004: Prescriptions for pleasure. Mental Health Today, June, 20-23.

Busby, H., Elliott, H., Popay, J. and Williams, G. 1999: Primary care and public health - a necessary relationship. Health and Social Care in the Community 7, 239-41.

Clarke, K., Sarre, S., Glendinning, C. and Datta, J. 2001: Providing family support in primary care: evaluation of the WellFamily service. Manchester: University of Manchester.

Coid, D.R., Williams, B. and Crombie, I.K. 2003: Partnerships with health and private voluntary sector organizations: what are the issues for health authorities and boards? Public Health 117, 317-22.

Crombie, I.K. and Coid, D.R. 2000: Voluntary organisations: from Cinderella to white knight? British Medical Journal 320, 419.

Crowley, P., Green, J., Freake, D. and Drinkwater, C. 2002: Primary Care Trusts involving the community: is community development the way forward? Journal of Management in Medicine 16, 311-22.

Daykin, N. and Naidoo, J. 1997: Poverty and health promotion in primary health care: professionals' perspectives. Health and Social Care in the Community 5, 309-17.

Department of Health. 2002: Shifting the balance of power: the next steps. London: Department of Health.

Department of Health. 2004: Making partnerships work for patients, carers and service users. London: Department of Health.

Department of Health. 2006: Practice based commissioning: practical implementation. London: Department of Health.

Department of Health. 2007: Welcoming social enterprise into health and social care. A resource pack for social enterprise providers and commissioners. Leeds: Department of Health.

Faulkner, M. 2004: Supporting the psychosocial needs of patients in general practice: the role of a voluntary referral service. Patient Education and Counselling 52, 41-46.

Fawcett, B. and South, J. 2005: Community involvement and Primary Care Trusts: the case for social entrepreneurship. Critical Public Health 15, 191-204.

Fisher, B. 2001: Community development in primary care. In Gillam, S., and Brooks, F., editors. New beginnings. Towards patient and public involvement in primary health care. London: Kings Fund.

Friedli, L. and Watson, S. 2004: Social prescribing for mental health. Durham: Northern Centre for Mental Health.

Godinho, J., Rathwell, T., Gott, M., Giraldes, M.R. and Daley, J. 1992: Tipping the balance towards Primary Health Care: understanding and investigating the agenda for change. European Journal of Public Health 2, 134-42.

Grant, C., Goodenough, T., Harvey, I. and Hine, C. 2000: A randomized controlled trial and economic evaluation of a referrals facilitator between primary care and the voluntary sector. British Medical Journal 320, 419-23. 
Greasley, P. and Small, N. 2005: Providing welfare advice in general practice: referrals, issues and outcomes. Health and Social Care in the Community 13, 249-58.

Gulbrandson, P., Fugelli, P., Sandvik, L. and Hjortdahl, P. 1999: Influence of social problems on management in general practice: multipractice questionnaire survey. British Medical Journal 317, 28-32.

Johnson, N., Jenkinson, S., Kendall, I., Bradshaw, Y. and Blackmore, M. 1998: Regulating for quality in the voluntary sector. Journal of Social Policy 27, 307-28.

Levenson, R. and Johnson, L. 2000: Improving health at local level. The role of primary care. London: Kings Fund.

Lewis, J 1999: The concepts of community care and primary care in the UK: the 1960s to the 1990s. Health and Social Care in the Community 7, 333-41.

Milligan, C. 1998: Pathways of dependence: the impact of health and social care restructuring - the voluntary experience. Social Science and Medicine 46, 743-53.

Milne, D., McAnaney, A., Pollinger, B., Batemen, $\mathbf{K}$. and Fewster, E. 2004: Analysis of the forms, functions and facilitation of social support in one English county: a way for professionals to improve the quality of health care. International Journal of Health Care Quality Assurance 17, 294-301.

Patton, M.Q. 1987: How to use qualitative methods in evaluation. London: Sage.

Peckham, S. and Exworthy, M. 2003: Primary care in the UK. Policy, organisation and management. Basingstoke: Palgrave Macmillan.

Peckham, S., Turton, P. and Taylor, P. 1998: The missing link. Health Service Journal May, 22-23.

Reason, P. and Heron, J. 2004: A layperson's guide to cooperative inquiry. Centre for Action Research in Professional Practice, University of Bath. Retrieved 14 February 2008 from http://www.bath.ac.uk/carpp/publications/coop_inquiry. html

Rogers, B. and Robinson, E. 2004: The benefits of community engagement. A review of evidence. London: Active Citizenship Centre, Home Office.
Royal College of General Practitioners. 2005: Inner city general practice. RGCP Information Sheet No. 20.

Secretary of State for Health. 2006: Our health, our care, our say: a new direction for community services. London: The Stationary Office.

Sherratt, M., Jones, K. and Middleton, P. 2000: A citizens advice service in primary care: improving patient access to benefits. Primary Health Care Research and Development $1,139-46$.

Social Services Inspectorate. 2000: Towards a common cause 'A compact for care'. Inspection of local authority social services and voluntary sector working relationships. London: Department of Health.

Taylor, M. 1997: The best of both worlds. The voluntary sector and local government. London: Joseph Rowntree Foundation.

Vedsted, P. and Christensen, M.B. 2005: Frequent attenders in general practice care: a literature review with special reference to methodological considerations. Public Health $119,118-37$.

Wakeling, D. 1999: Unlimited menu? The crisis care continuum and the non-statutory sector. Journal of Mental Health 8, 547-50.

Ward, D. 2001: Working with non-statutory agencies. Journal of Community Nursing 15.

Weir, B. 2002: Partnership working for health. A baseline survey of partnerships for health improvement and health care between voluntary and statutory sectors. Retrieved 18 February 2008 from http://www.vhscotland.org.uk/library/ vhs/Partnership \%20working\%20for\%20Health,\%20December \%202002\%20report.pdf

Woodall, J. and South, J. 2005: The evaluation of the CHAT social prescribing scheme in Bradford South \& West $P C T$. Centre for Health Promotion Research, Leeds Metropolitan University.

Zantinge, E.M., Verhaak, P.F.M. and Bensing, J.M. 2005: The workload of GPs: patients with psychological and somatic problems. Family Practice 22, 293-97. 